\title{
Wear Properties of the Surface Alloyed AISI 1020 Steel with Vanadium and Boron by TIG Welding Technique
}

\author{
E. ABAKAY, S. SEN* AND U. SEN \\ Sakarya University, Engineering Faculty, Department of Metallurgy and Materials Engineering \\ Esentepe Campus, 54187 Sakarya, Turkiye
}

\begin{abstract}
It is now well known that surface alloying caused improvement in the mechanical/chemical properties of near surface regions of materials. In the present study, surface alloying treatment with boron, vanadium and iron on the AISI 1020 steel was realized by the technique of TIG welding. Ferrous boron, ferrous vanadium and Armco iron were used for surface alloying treatment. Before the treatment, ferrous alloys were ground and sieved to be smaller than $38 \mu \mathrm{m}$. The powders were mixed to be composed of $\mathrm{Fe}_{15-x} \mathrm{~V}_{x} \mathrm{~B}_{5}$, where $x=1,3$, and 5 (by at.). Prepared powders were pressed on the steel substrate and melted by TIG welding for surface alloying. Coated layers formed on the steel substrate were investigated using scanning electron microscopy, X-ray diffraction analysis and Vickers microhardness testers. It was shown that the surface alloyed layer has a composite structure including steel matrix and eutectic borides. Wear tests of the surface alloyed AISI 1020 steels were realized against WC-Co ball using ball-on-disk method.
\end{abstract}

DOI: $10.12693 /$ APhysPolA.125.251

PACS: 52.77.Fv, 81.40.Cd, 81.40.Ef, 81.05.Je, 81.40.-z, 81.40.Pq

\section{Introduction}

The hard facing alloys obtained using high-energy density sources such as electron beam welding, plasma arc, and laser have been widely applied to enhance the wear and corrosion resistance of material surface [1-5]. The gas tungsten arc welding (GTAW) process (also called TIG welding) is used when a good weld appearance and a high quality of the weld are required. In this process, an electric arc is formed between a tungsten electrode and the base metal. The arc region is protected by a kind of inert gas or a mixture of inert gases. The tungsten electrode is heated to temperatures high enough for the emission of the electrons necessary for the operation of the arc [6]. Vanadium and iron are a strong boride-forming element, which forms stabile borides like FeB, $\mathrm{Fe}_{2} \mathrm{~B}, \mathrm{VB}, \mathrm{V}_{2} \mathrm{~B}_{3}$, etc. [7-11]. These compounds have high melting temperature, hardness and wear resistance like $\mathrm{Zr}$, Ti and $\mathrm{Cr}$ borides [7-9]. While there is a great deal of study about surface hardening processes of vanadium-containing steel and alloys [8,10-12], there is not enough study about the $\mathrm{Fe}-\mathrm{V}-\mathrm{B}$ alloys used for surface alloying treatments.

In this investigation, GTAW process is used as a high energy density beam to form a high vanadium $\mathrm{Fe}-\mathrm{V}-\mathrm{B}$ hard surface above the AISI 1020 steel with a powder mixtures consisting of ferrous vanadium, ferrous boron and iron. Main objective of the study is wear properties of the surface alloyed steels with $\mathrm{Fe}_{15-x} \mathrm{~V}_{x} \mathrm{~B}_{5}$, where $x=$ 1,3 and 5 (by at.) alloy against $\mathrm{WC}-\mathrm{Co}$.

*corresponding author; e-mail: sdmnsen@sakarya.edu.tr

\section{Experimental procedure}

The substrate material for the welding surface was prepared from AISI 1020 steel plates. Before welding, these specimens were ground and cleaned with acetone to remove any oxide and grease and then dried with compressed air. The nominal composition of ferrous vanadium alloys used in the study (wt\%) was as follows: $79.27 \% \mathrm{~V}, 0.21 \% \mathrm{C}, 0.95 \% \mathrm{Al}, 0.98 \% \mathrm{Si}$, and balance Fe. Ferrous boron and vanadium were grounded by ring grinder and sieved to be $38 \mu \mathrm{m}$ particle sizes.

Ball-on-disk arrangement was used for friction and wear test. The $\mathrm{WC}-\mathrm{Co}$ ball, $10 \mathrm{~mm}$ in diameter, was used in the wear test. The $\mathrm{WC}-\mathrm{Co}$ ball has mirror like surface finish. Most of the materials are encountered with ambient temperature and humidity in the industrial applications. Therefore, the friction and wear tests were carried out at room temperature $\left(21 \pm 3{ }^{\circ} \mathrm{C}\right)$, relative humidity being $64 \pm 5$ conditions. Wear tests were carried out under the loads of $2.5,5$, and 10 at $0.1 \mathrm{~m} / \mathrm{s}$ sliding speed. Mean Hertzian contact pressures [13] calculated for $\mathrm{WC}-\mathrm{Co}$ ball under the loads of $2.5,5$, and $10 \mathrm{~N}$ are $410,520,650 \mathrm{~N} / \mathrm{mm}^{2}$, respectively. Knowing that, the compressive yield strength of $\mathrm{WC}-\mathrm{Co}$ ball is $4510 \mathrm{MPa}$.

\section{Results and discussion}

Surface alloying modification by ferrous boron and ferrous vanadium filler alloys was realized by means of TIG welding. In the process, a thin surface layer of the base metal were simultaneously melted together with ferrous alloys and then rapidly solidified to form a dense coating bonded to the base metal. Surface alloyed layer consists of iron, boron and vanadium. Figure 1 shows cross-sectional micrographs of the alloyed layers of the $\mathrm{Fe}_{15-x} \mathrm{~V}_{x} \mathrm{~B}_{5}$, where $x=1,3$ and 5 (by at.) alloys. 

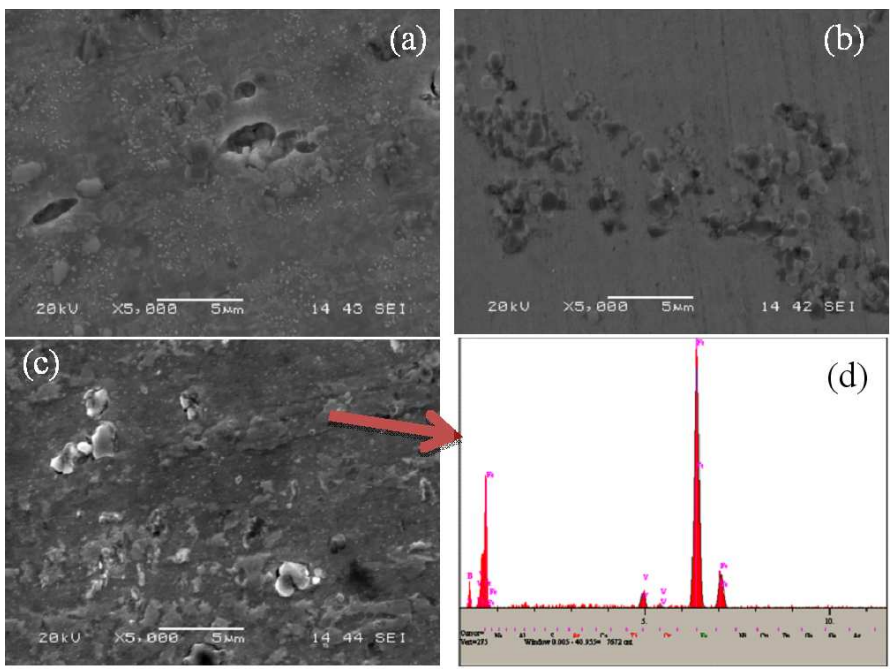

Fig. 1. SEM micrographs of the $\mathrm{Fe}_{15-x} \mathrm{~V}_{x} \mathrm{~B}_{5}$ alloys for (a) $x=1$, (b) $x=3$, and (c) $x=5$, respectively, (d) EDS analysis of borides.

The thickness of the hard-faced layer ranged from 2 to $3 \mathrm{~mm}$. The melted surfaces of the surface alloyed steel have smooth and rippled surface topography.

The phases formed in the surface alloyed layer consist of $\mathrm{Fe}_{4} \mathrm{~V}, \mathrm{Fe}_{2} \mathrm{~B}$, and $\mathrm{VB}$ phases. Microstructural examinations of the alloyed surface layer showed that three distinct regions took place on the cross-section of the surface alloyed steels which were alloyed layer consisting of boride phases near the grain boundaries of steel matrix. As shown from Fig. 1 the increase of vanadium content in the alloy composition caused the increase of boride phases which took place in the alloyed layers. As seen in Fig. 1, borides formed in the in situ composite structure found in the alloyed layer include primary borides and steel matrix between borides. The results are supported by phase diagram of $\mathrm{B}-\mathrm{Fe}-\mathrm{V}$ [13]. Some parts of the alloyed layer have much more dense boride phase in the alloyed layer as seen in Fig. 1. It is possible that these parts of the alloyed layer consist of $\mathrm{VB}$ and $\mathrm{Fe}_{2} \mathrm{~B}$ phases which were detected by XRD analysis. Eroglu [14] and Bourithis and Papadimitriou [15] studied the boron addition to the steel surface for surface alloying and they explained that the borides formed in the alloyed layer realized close up the grain boundaries.

The hardness of the boride phases and matrix of the alloyed layer and steels' un-coated layer are $1621 \pm$ $20 \mathrm{HV}_{0.01}, 180 \pm 21 \mathrm{HV}_{0.01}$ and $155 \pm 15 \mathrm{HV}_{0.1}$, respectively. As known, the hardness of the boride phases is changing in the range 1600-5000 HV [16]. Figure 2a shows the variation of friction coefficients as a function of applied load with different alloyed layers against WC-Co ball at the sliding speed of $0.1 \mathrm{~m} / \mathrm{s}$ for $250 \mathrm{~m}$ sliding distance. It is clear from this figure that the effect of the vanadium content and applied load on the friction coefficient does not have an important effect. As shown from the figure the increase in vanadium content caused

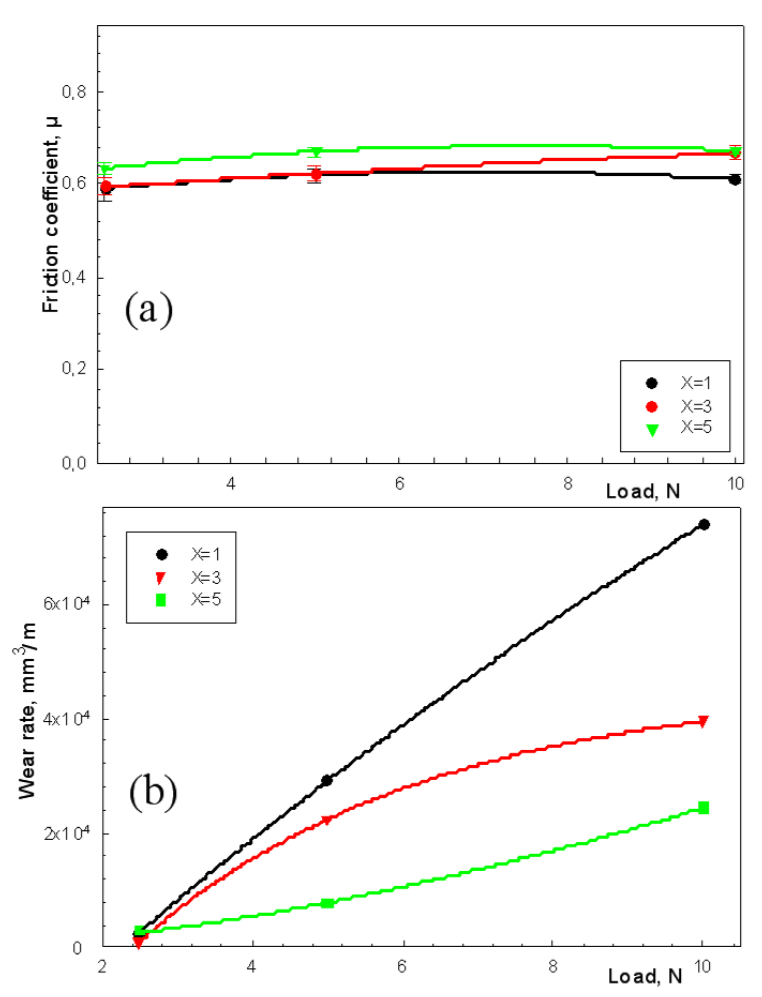

Fig. 2. (a) Friction coefficient and (b) wear rate of surface alloyed AISI 1020 steel with $\mathrm{Fe}_{15-x} \mathrm{~V}_{x} \mathrm{~B}_{5}$ alloys.

the increase of the friction coefficient between $3.3 \%$ and $12.1 \%$ according to applied load.

Figure $2 \mathrm{~b}$ presents the wear rate of the surface alloyed AISI 1020 steel with $\mathrm{Fe}_{15-x} \mathrm{~V}_{x} \mathrm{~B}_{5}$, alloys for $x=1,3$ and 5 against $\mathrm{WC}-\mathrm{Co}$ ball. As shown from the figure, the increase in applied load caused the increase of wear rate for all alloy compositions. The Archard equating shows that increasing load reasoned the increase of wear rate [17]. As shown from the figure, increase in vanadium content in the alloy composition caused the decrease of the wear rate according to applied load. As described previously, increase in vanadium concentration in the alloy composition caused the higher content of the boride phases in the surface alloyed layers. Increase in the vanadium content in the alloy composition from $5 \%$ to $25 \%$ caused to decrease the wear rate between $15 \%$ and $67 \%$ according to applied load. However, load is effective parameter in the wear test which is caused to increase the wear rate between $718 \%$ and $3894 \%$ according to vanadium content of the alloys.

Some scuffing, abrasive scratches and its deep grooves and some smeared oxidative zones were realized on the wear track. WC-Co ball is a famous abrading counterface for the tribological applications [18]. In general, WC-Co is used for the abrasive applications and machining process of the metals in industry. The wear mechanism was abrasive-oxidative. 


\section{Conclusions}

1. It has been proven that surface alloying treatment of AISI 1020 steel using $\mathrm{Fe}_{15-x} \mathrm{~V}_{x} \mathrm{~B}_{5}$ alloys for $x=$ 1,3 , and 5 was realized by TIG welding.

2. Surface alloyed layer consists of iron, boron, and vanadium confirmed by EDS analysis and the melted surfaces of the surface alloyed steel present a smooth and rippled surface topography.

3. Hard faced layers of the steel consist of $\mathrm{Fe}_{4} \mathrm{~V}, \mathrm{Fe}_{2} \mathrm{~B}$, and VB phases.

4. Increase of the vanadium content in the alloy composition caused to increase of boride phases formed in the alloyed layers.

5. The hardness of the boride phases and matrix of the alloyed layer and steels' un-coated layer are $1621 \pm$ $20 \mathrm{HV}_{0.01}, 180 \pm 21 \mathrm{HV}_{0.01}$ and $155 \pm 15 \mathrm{HV}_{0.1}$, respectively.

6. The effect of the vanadium content and applied load on the friction coefficient of the surface alloyed layers against $\mathrm{WC}-\mathrm{Co}$ does not have an important effect.

7. Increase in applied load on the wear test caused the increase of wear rate for all alloy compositions and increase in vanadium content in the alloy composition caused the decrease of wear rate according to applied load.

8. SEM and EDS analysis showed that the wear mechanism of the surface alloyed steel with $\mathrm{Fe}_{15-x} \mathrm{~V}_{x} \mathrm{~B}_{5}$, alloys against $\mathrm{WC}-\mathrm{Co}$ was abrasive and oxidative.

\section{References}

[1] A.K. Chattopadhyay, L. Chollet, H.E. Hintermann, J. Mater. Sci. 26, 5093 (1991).

[2] Q.Y. Hou, J.S. Gao, F. Zhou, Surf. Coat. Technol 194, 238 (2005).

[3] R.G. Wellman, J.R. Nicholls, Wear 242, 80 (2000).

[4] M. Eroglu, N. Ozdemir, Surf. Coat. Technol. 154, 209 (2002).

[5] K. Hyung-Jun, Y. Byoung-Hyun, L. Chang-Hee, Wear 249, 846 (2002).

[6] C. Fan, M.C. Chen, C.M. Chang, W. Wu, Surf. Coat. Technol. 201, 908 (2006).

[7] R.A. Cutler, S.J. Jr. Schneider, Engineered Materials Handbook: Ceramics and Glasses, 4 ASM Int., Materials Park $(\mathrm{OH})$ 1991, p. 787.

[8] N. Gidikova, Mater. Sci. Eng. 278, 181 (2000).

[9] A. Erdemir, M. Halter, G.R. Fenske, Wear 205, 236 (1997).

[10] K.H. Habig, R. Chatterjee-Fischer, Tribol. Int. 1112, 209 (1981).

[11] S. Sen, Surf. Coat. Technol. 190, 1 (2005).

[12] J. Phase Equilibria Diffus. 33, No. 5 (2012).

[13] A. Samuel, J. Weir, Introduction to Engineering Design, Butterworth-Heinemann, Oxford 1999, p. 107.

[14] M. Eroglu, Surf. Coat. Technol. 203, 2229 (2009).

[15] L. Bourithis, G. Papadimitriou, Mater. Lett. 57, 1835 (2003).

[16] İ. Özbek, Borlama, C. Yüzeylerin Kaplanması, E. Bilim, in: Surface Coating of Steels in: Science and Technology Series, Zonguldak, Erdemir 2006, p. 118 (in Turkish).

[17] V.K. Rai, R. Srivastava, S.K. Nath, S. Ray, Wear 231, 265 (1999).

[18] D.A. Stewart, P.H. Shipway, D.G. McCartney, Wear 225-229, 789 (1999). 